\title{
Antifungal activity of pomegranate peel extract and isolated compound punicalagin against dermatophytes
}

\author{
Simone R Foss ${ }^{1}$, Celso V Nakamura ${ }^{2}$, Tania Ueda-Nakamura ${ }^{2}$, Diógenes AG Cortez ${ }^{3}$, Eliana H Endo ${ }^{4}$ \\ and Benedito P Dias Filho ${ }^{2^{*}}$
}

\begin{abstract}
Background: Dermatophyte species infect the epidermis and appendages, often with serious social and health-economic consequences. The hydroalcoholic extract of pomegranate fruit peel showed activity against the dermatophyte fungi Trichophyton mentagrophytes, T. rubrum, Microsporum canis and M. gypseum.

Methods: Hydroalcoholic extract was prepared with pomegranate peels. This crude extract was fractionated and submitted to liquid-liquid partition, resulting in an active fraction which was fractionated in a Sephadex LH-20 column, followed by a Lobar column. The structure of the active compound was established with the use of spectroscopic methods.

Results: The crude extract of pomegranate fruit peel showed activity against the dermatophytes Trichophyton mentagrophytes, T. rubrum, Microsporum canis, and M. gypseum, with MICs values of $125 \mu \mathrm{g} / \mathrm{ml}$ and $250 \mu \mathrm{g} / \mathrm{ml}$, respectively for each genus. Punicalagin was isolated and identified by spectroscopic analysis. The crude extract and punicalagin showed activity against the conidial and hyphal stages of the fungi. The cytotoxicity assay showed selectivity for fungal cells than for mammalian cells.

Conclusions: These results indicated that the crude extract and punicalagin had a greater antifungal activity against T. rubrum, indicating that the pomegranate is a good target for study to obtain a new antidermatophyte medicine.
\end{abstract}

\section{Background}

Dermatophytes are fungi that use keratin for their nutrition and may cause infections of the nails, skin, and hair, known as dermatophytosis. These organisms are classified into three genera: Epidermophyton, Trichophyton, and Microsporum [1]. Although not life-threatening, superficial mycoses due to dermatophytes have been among the most common communicable diseases of humans since antiquity, and have considerable social and healtheconomic implications [2].

Generally, dermatophytes infect the superficial layers of skin. However, immunocompromised patients, such as AIDS patients or recipients of kidney transplants, can be affected by deep injury in the dermal layer, resulting in

\footnotetext{
* Correspondence: bpdfilho@uem.br

${ }^{2}$ Department of Health Sciences, Universidade Estadual de Maringá, Maringá, PR, Brazil

Full list of author information is available at the end of the article
}

disseminated lesions that may take fatal forms [3-6]. Although many antifungals are available, their side effects and drug interactions, and the existence of resistant organisms have created a need to find safer and more effective treatments [7]. Also, dermatophytosis treatments are, in general, expensive and must be applied over long periods.

Natural products have proven to be an alternative source of new active molecules. In many countries, mainly in developing countries, plants have been used as the primary basic health treatment. The pomegranate Punica granatum is a bush 3 to 5 meters in height, with opposite and obtuse leaves, flowers with wrinkled white, yellow, or orange petals. The fruit is composed of a yellow to red peel that covers the seeds, the fleshy arils of which are eaten. Punica granatum is a plant with worldwide application in folk medicine. There are references to an antimicrobial effect of pomegranate products against many pathogenic bacterial species, including inhibition of formation of 
biofilms [8-11], antiplasmodial activity, and effects against Entamoeba histolytica and Giardia lamblia [12]. Polyphenols extracted from pomegranate fruit rind were active against phytopathogenic fungi [13]. The extract of $P$. granatum showed good results as a topical antifungal agent for the treatment of candidosis associated with denture stomatitis [14]. The tannin punicalagin is the major component of pomegranate fruit peel. This substance was isolated not only from Punica granatum, but also was described from Terminallia mollis and Terminallia brachystemma, as having antifungal activity against Candida albicans, C. krusei, and C. parapsilosis [15].

The present study evaluate the antidermatophyte activity of pomegranate fruit peel extract and investigate its effect on different fungal development stages, cytotoxicity and possible mechanisms of action. The active substance of pomegranate peel was isolated and identified as well.

\section{Methods}

Plant material and crude extract

Punica granatum fruits were collected in December 2007 in Maringá, Paraná, Brazil. The peel was separated manually (2183.8 g) and extracted with a 90\% (v/v) hydroalcoholic solution, by maceration at room temperature for 5 days in a dark room. The hydroalcoholic extracts were filtered, evaporated under vacuum at $40^{\circ} \mathrm{C}$, lyophilized, and kept in a freezer at $-10^{\circ} \mathrm{C}$. This crude extract was assayed against four species of dermatophyte fungi and Gram-positive and Gram-negative bacteria.

\section{Isolation of the active substance}

First, $200 \mathrm{ml}$ of an aqueous solution of the crude extract $(20 \mathrm{~g})$ was submitted to liquid-liquid partition, and eluted with ethyl acetate and then with $n$-butanol; this procedure was repeatead four times with each solvent, resulting in three fractions: F1 (water), F2 (ethyl acetate), and F3 (n-butanol). The collected fractions were evaporated under vacuum and lyophilized in the same conditions as for the extract. Second, $0.5 \mathrm{~g}$ of the fraction with the best activity (F1) was dissolved in water, filtered through cotton wool and then placed in a Sephadex LH-20 column. The procedure was performed twice to maximize the yield. It was monitored by thinlayer chromatography (TLC), mobile phase $n$-butanol: acetic acid: water (40:10:50), and observed as a natural yellow substance. Finally, after antifungal tests, the active subfraction was placed in a Lobar (C-18) column and eluted with methanol:water (1:1), also monitored by TLC. The structure of the active compound was established with the use of spectroscopic methods (EI-MS, ${ }^{1} \mathrm{H}$ NMR, ${ }^{13} \mathrm{C}$ NMR, H-H COSY, HMBC, HMQC, and DEPT). The isolated substance was tested against Trichophyton rubrum.

\section{Microorganisms and growth conditions}

Dermatophyte species used for this investigation were Microsporum canis ATCC 32903, Microsporum gypseum ATCC 14683, Trichophyton mentagrophytes ATCC 1481 and Trichophyton rubrum ATCC 28189. Gram-negative bacteria Pseudomonas aeruginosa ATCC 27853 and Escherichia coli ATCC 25922 and Gram-positive bacteria Bacillus subtilis ATCC 6623 and Staphylococcus aureus ATCC 25923 were also investigated, because secondary infections may occur in dermatophytoses.

\section{Microdilution broth assay}

Antifungal and antibacterial assays were performed by microdilution method in sterile flat-bottom microplates according to CLSI $[16,17]$. Each well contained appropriate test samples, culture medium, and approximately $10^{5}$ cells for bacteria, and $10^{4}$ spores in a total volume of $100 \mu \mathrm{l}$. The plates were incubated at $37^{\circ} \mathrm{C}$ and $24 \mathrm{~h}$ for bacteria and $28^{\circ} \mathrm{C}$ during $72 \mathrm{~h}$ for dermatophytes. The MIC (Minimal Inhibitory Concentration) was defined as the lowest concentration of a compound at which the microorganism tested did not demonstrate visible growth. To determine the minimal fungicidal effect, $10 \mu \mathrm{l}$ of suspension from the MIC was spotted in Sabouraud agar and incubated for 24 to $72 \mathrm{~h}$ at $28^{\circ} \mathrm{C}$. The minimum fungicidal concentration (MFC) was defined as the lowest concentration that yielded negative subcultures or only one colony.

\section{Conidial germination inhibition assay}

Different concentrations of test samples in $90 \mu \mathrm{l}$ were prepared in 96-well flat-bottom micro-culture plates by the double dilution method. The wells were prepared in duplicate for each concentration. An inoculum of $10 \mu \mathrm{l}$ of spore suspension containing 2000-3000 spores was added to each well. Plates were incubated at $28^{\circ} \mathrm{C}$ for $24 \mathrm{~h}$ and then examined for spore germination under an inverted microscope. For analysis, spores were considered germinated if they had a germ tube at least twice the length of the spore.

\section{Disc diffusion method}

Disc diffusion method and fluorescence microscopy were used to evaluate the hyphal growth inhibition. Plates with Sabouraud Dextrose Agar were centrally inoculated with T. rubrum and incubated at $28^{\circ} \mathrm{C}$ for 3-5 days. Test discs were made with the extract, punicalagin, and Nystatin, with concentrations close to the MIC. These discs and one control disc (with $10 \mu \mathrm{l}$ of sterile water) were arranged around the colony on the plate, at a distance of $0.5 \mathrm{~cm}$, and incubated at $28^{\circ} \mathrm{C}$ for $72 \mathrm{~h}$. The hyphal growth inhibition was evaluated visually and photographed [18].

\section{Fluorescence microscopy}

Sub-inhibitory concentrations of the crude extract in $500 \mu \mathrm{l}$ of culture medium were prepared by the double-dilution 
method, in 24-well flat-bottom micro-culture plates, on which round cover slips were placed. The wells were prepared in duplicate for each concentration. The wells were inoculated with $50 \mu \mathrm{l}$ of spore suspension, containing 10,000-15,000 spores. The plates were incubated at $28^{\circ} \mathrm{C}$ for $24 \mathrm{~h}$. Then, the cover slips carefully removed were and washed in PBS, pH 7.2, with light manual shaking. Next, the medium was carefully removed and cover slips with adhered cells were stained with Calcofluor White M2R (Sigma, St. Louis, MO, USA) and mounted on a slide with synthetic resin (Araldite $502^{\mathrm{mw}}$ ). Slides were viewed by means of a Zeiss fluorescent microscope [19].

\section{Cytotoxicity assay}

Confluent Vero cell monolayers grown in 96-well cellculture plates were incubated with a tenfold serial dilution of punicalagin, starting with a concentration of $1000 \mu \mathrm{g} /$ $\mathrm{ml}$ - for $48 \mathrm{~h}$ at $37^{\circ} \mathrm{C}$ and $5 \% \mathrm{CO}_{2}$. At that time, cultures fixed with $10 \%$ trichloroacetic acid for $1 \mathrm{~h}$ at $4^{\circ} \mathrm{C}$ were stained for $30 \mathrm{~min}$ with $0.4 \%$ sulforhodamine B (SRB) in $1 \%$ acetic acid and subsequently washed with distilled water. Bound SRB was solubilized with $150 \mathrm{ml} 10 \mathrm{mM}$ Tris-base solution. Absorbance was read in an ELISA plate reader at $530 \mathrm{~nm}$. The cytotoxicity was expressed as a percentage of the optical density compared to the control.

\section{Results and discussion}

\section{Isolation of active substance}

From $2183.8 \mathrm{~g}$ of pomegranate fruit peel, $220.6 \mathrm{~g}$ of crude extract was obtained, a yield of $10.1 \%$. Pomegranate fruit peel is rich in tannins, high-molecular-weight plant polyphenols, which can be classified into two chemically and biologically distinct groups: condensed tannin and hydrolyzable tannin, the latter composed of phenolic acids and glycosyl esters. Hydrolyzable tannins are separated into ellagitannins (containing ellagic acid) and gallotannins (containing gallic acid) [20]. The structure of active compound, punicalagin, obtained by successive bioactiveguided steps, was established by spectroscopic methods (EI-MS, ${ }^{1} \mathrm{H}$ NMR, ${ }^{13} \mathrm{C}$ NMR, H-H COSY, HMBC, HMQC, and DEPT). Punicalagin has been isolated from plants [21] by different methods. However, some of the isolation techniques, such as high-speed countercurrent chromatography, require expensive apparatus [22]. The present method is a less expensive alternative to obtain punicalagin with excellent results, and resembles a purification procedure reported [23]. The spectral analysis was compared with that reported by Doig et al. [24], which confirmed the isolated substance as punicalagin. The mass spectrum (EI-MS) of the punicalagin isolated confirmed to that reported by Seeram et al. [23]. Punicalagin anomers can be observed in the mass spectrum, which show double chemical shifts at the same carbon or hydrogen.
Punicalagin FAB-MS at $m / z$ 1083.4 found $\mathrm{C}_{48} \mathrm{H}_{28} \mathrm{O}_{30}$. The ${ }^{13} \mathrm{C}$ NMR results: $\delta 88.78(\mathrm{C}-1), 69.73(\mathrm{C}-2), 75.33$ (C-3), 73.13 (C-4), 65.38 (C-5), 63.23 (C-6), 168.26 (C-7), 124.59 (C-8), 105.61/108.71 (C-9), 144.72 (C-10), 135.67 (C-11), 144.72 (C-12), 114.42 (C-13), 113.87 (C-14), 144.62 (C-15), 135.5 (C-16), 144.4 (C-17), 105.02/108.71 (C-18), 124.24 (C-19),168.45/148.57 (C-20), 167.6 (C-21), 123.57 (C-22), 109.51 (C-23), 144.39 (C-24), 137.76 (C-25), 144.39 (C-26), 117.7 (C-27), 109.51 (C-28), 147.35 (C-29), 136.86 (C-30), 135.5 (C-31),112/113.37 (C-32), 121.75/121.87 (C-33), 157.81 (C-34), 112.56/113.37 (C-35), 135.18 (C-36),136.86/139.2 (C-37), 147.35 (C-38), 109.51 (C-39), 121.75/121.87 (C-40), 157.3 (C-41),113.87 (C-42), 144.36 (C-43), 134.88 (C-44), 144.11 (C-45), 105.02/108.71 (C46), 124.59 (C-47), 168.20 (C-48). $\mathrm{HMBC}^{1} \mathrm{H}_{-}{ }^{13} \mathrm{C}$ and ${ }^{1} \mathrm{H}$ results: 5.06/5.13 $(\mathrm{H}-\mathrm{C} 1, m), 4.65 / 4.71(\mathrm{H}-\mathrm{C} 2, m), 5.06 /$ 5.13 (H-C3, $m$ ), 4.65/4.71 (H-C4, $m$ ), 3.09/3.17 (H-C5, $m$ ),

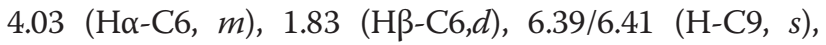
6.28/6.41 (H-C18, s), $6.7(\mathrm{H}-\mathrm{C} 23, s), 6.28 / 6.41(\mathrm{H}-\mathrm{C} 46, s)$.

\section{Antifungal effect}

Crude extract from pomegranate showed a considerable inhibitory effect against both genera Trichophyton and Microsporum (Table 1) with MIC of 125 and $250 \mu \mathrm{g} / \mathrm{ml}$, respectively. Results of specific tests against T. rubrum are presented in Table 2. The isolated compound punicalagin showed about the same MIC value as the crude extract, probably because punicalagin is the majority substance. Nystatin showed MIC of $0.39 \mu \mathrm{g} / \mathrm{ml}$ for all dermatophytes tested. The minimal fungicidal concentration of the crude extract against T. rubrum was within two-twofold dilution of the MIC for this organism. Plant products tested for use against dermatophytes have shown activity against T. rubrum $[19,25,26]$. Although the mechanisms of action were not elucidated, we eliminated the possibility of complexation with the membrane ergosterol (data not shown)

\section{Table 1 Minimal inhibitory concentration (MIC)}

\begin{tabular}{ll}
\hline Microorganisms & MIC $(\boldsymbol{\mu g} / \mathbf{m l})$ \\
\hline Bacteria & \\
Staphylococcus aureus & 62.5 \\
Bacillus subtilis & 62.5 \\
Pseudomonas aeruginosa & 250 \\
Escherichia coli & $>1000$ \\
Dermatophytes & \\
Trichophyton rubrum & 125 \\
Trichophyton mentagrophytes & 125 \\
Microsporum gypseum & 250 \\
Microsporum canis & 250 \\
\hline
\end{tabular}

Minimal inhibitory concentration (MIC) of crude extract of Punica granatum against bacteria and dermatophytes species. 
Table 2 Antifungal activity $(\mu \mathrm{g} / \mathrm{ml})$ against Trichophyton rubrum

\begin{tabular}{|c|c|c|c|}
\hline & \multicolumn{3}{|c|}{$\begin{array}{l}\text { Antifungal activity }(\mu \mathrm{g} / \mathrm{ml}) \text { against Trichophytor } \\
\text { rubrum }\end{array}$} \\
\hline & $\overline{M I C}$ & MFC & CGI \\
\hline Crude extract & 125 & 250 & 62.5 \\
\hline \multicolumn{4}{|l|}{ Fractions } \\
\hline P1 & 125 & 125 & 62.5 \\
\hline P2 & 250 & 250 & - \\
\hline P3 & 125 & 125 & - \\
\hline Punicalagin & 62.5 & 125 & 62.5 \\
\hline Nystatin & 0,78 & - & 0,39 \\
\hline
\end{tabular}

Minimal inhibitory concentration (MIC), minimal fungicidal concentration (MFC) and conidal germination inhibition (CGI) of pomegranate fruit peel extract, fractions and the isolated substance punicalagin.

and observed no change in the morphology of the hyphal structures.

Under certain conditions, dermatophytosis can be complicated by secondary bacterial infections. Therefore, we investigated whether the hydroalcoholic extract exerts, in addition to its antifungal effects, a significant antibacterial activity against Gram-negative and Gram-positive bacteria. The crude extract from pomegranate showed good activity on S. aureus, B. subtilis and $P$. aeruginosa with MICs of $62.5,62.5$ and $250 \mu \mathrm{g} / \mathrm{ml}$. E. coli $\mathrm{MIC}>1000 \mu \mathrm{g} / \mathrm{ml}$ were considered resistant (Table 1).

\section{Conidial germination}

There are two phases of fungal growth, conidial germination and hyphal growth, in which drug action can occur. Conidial germination inhibition occurred at concentration of $62.5 \mu \mathrm{g} / \mathrm{ml}$ for both crude extract and punicalagin. $\mathrm{Ny}-$ statin was able to inhibit conidial germination at $0.39 \mu \mathrm{g} /$ $\mathrm{ml}$. This is particularly noteworthy because the MICs of crude extract and fraction extract were found to be
$125 \mu \mathrm{g} / \mathrm{ml}$. This similar effect of the extract and isolated substance is due to the fact that punicalagin is the majority substance in the pomegranate fruit peel [22].

\section{Disc diffusion}

Disc diffusion is simple and inexpensive agar-based method which enables the determination of activity of different substances against microrganisms. Here, the hyphal growth inhibition is shown with disc diffusion of crude extract and Nystatin in agar. In Figure 1, discs containing at least $250 \mu \mathrm{g} / \mathrm{ml}$ of crude extract inhibited hyphal growth of $T$. rubrum.

\section{Fluorescence microscopy}

Calcofluor White stain was used to show possible fungal cell wall alterations. Figure 2 shows strong inhibition of hyphal growth on T. rubrum treated with crude extract at $125 \mu \mathrm{g} / \mathrm{ml}$ (Figure 2B) and inhibition of conidial germination by punicalagin at $62.5 \mu \mathrm{g} / \mathrm{ml}$ (Figure 2C). Although no morphological alterations were detected, this procedure was important to understand and confirm the inhibition of the hyphal growth and conidial germination, using the same incubation conditions. This may be explained by the nature of the principal substance, punicalagin, which is a tannin. The tannins could act on the microorganism cell membrane, switching its metabolism; complexing with metallic ions needed for the microorganism's metabolism; and inhibiting fungal and bacterial enzymes by complexation with substrates [21].

\section{Cytotoxicity assay}

Cytotoxicity was monitored using SRB assays. Cell viability after exposure to $100 \mu \mathrm{g} / \mathrm{ml}$ of crude extract, fraction P1, and punicalagin was $83 \%, 99 \%$, and $90 \%$, respectively (data not shown). The concentration of punicalagin with $50 \%$ cytotoxicity $\left(\mathrm{CC}_{50}\right.$ value) on Vero cell was $400 \mu \mathrm{g} / \mathrm{ml}$, showing that punicalagin is 6.4 times more selective for

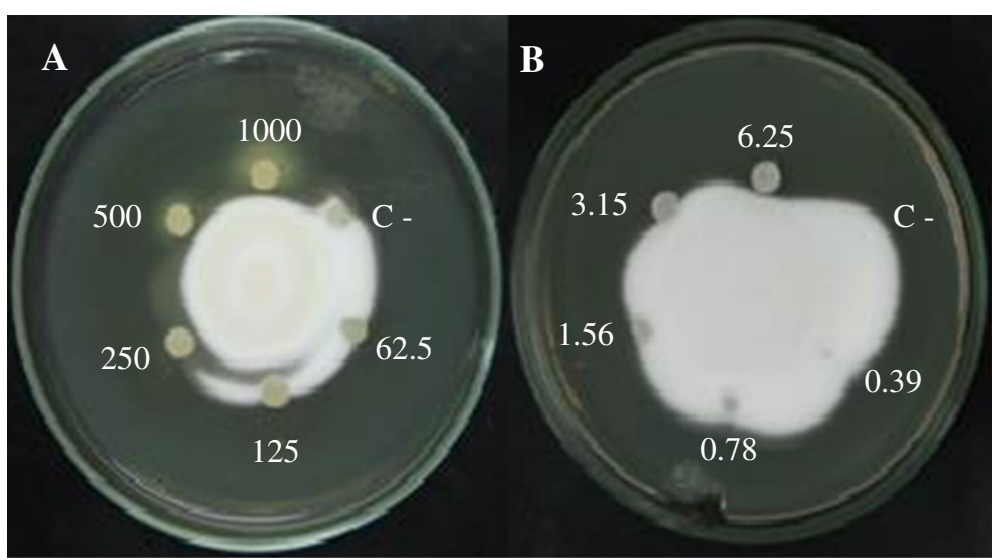

Figure 1 Disc diffusion method. Antifungal activity in solid medium against T. rubrum. (A) Crude extract - 1000, 500, 250, 125, 62.5 $\mu \mathrm{g} / \mathrm{ml}$. (B) Nystatin $-6.25,3.15,1.56,0.78,0.39 \mu \mathrm{g} / \mathrm{ml}$. Water was used as control (C-). Data correspond to one representative experiment out of three. 

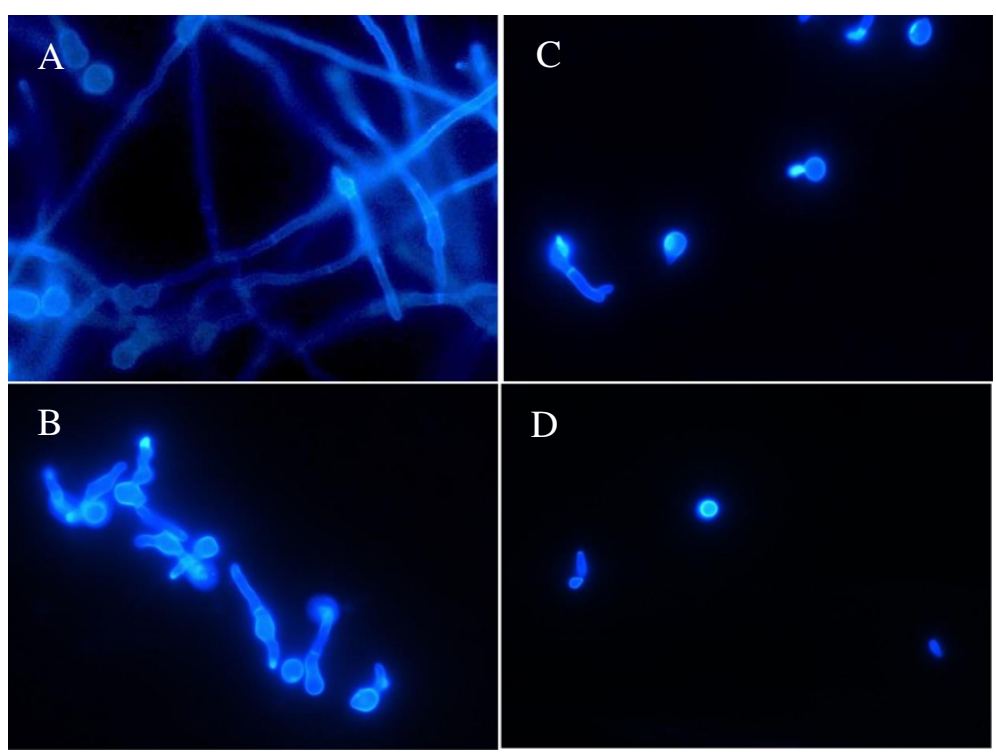

Figure 2 Fluorescence microscopy by Calcofluor White Stain. Spore germination inhibition of T. rubrum on cover slips. (A) Control cells; (B) Treated with $125 \mu \mathrm{g} / \mathrm{ml}$ crude extract; (C) Treated with $62.5 \mu \mathrm{g} / \mathrm{ml}$ punicalagin; (D) Treated with $0.78 \mu \mathrm{g} / \mathrm{ml}$ Nystatin. Data correspond to one representative experiment out of three.

fungi cells than for mammal cells, indicating that the crude extract may be ideal for use in topical form. The values of $\mathrm{CC}_{50}$ of punicalagin are similar to those that have been reported, with $\mathrm{CC}_{50}$ as $460 \mu \mathrm{g} / \mathrm{ml}$ [21]. The acute toxicity evaluated, in vivo, using Wistar rats with intranasal administration, and detected that the $\mathrm{LD}_{50}$ (the dose that can kill $50 \%$ of the assayed animals) was $731 \mathrm{mg} / \mathrm{ml}$ [27]. Pomegranate juice may contain $2 \mathrm{~g} / \mathrm{L}$ of punicalagin. Sprague-Dawley rats fed a diet containing 6\% punicalagin, for 37 days, showed no toxicity [28]. These data support the initial idea of a treatment with crude extract of pomegranate fruit peel in the topical form.

\section{Conclusions}

Pomegranate extract inhibited the growth of T. rubrum, $T$. mentagrophytes, M. canis and M. gypseum. Spectroscopic analyses revealed punicalagin as the active substance. The antidermatophyte assay, using Trichophyton rubrum as a model, showed that the crude extract acts on conidial and hyphal structures. Also, cytotoxicity assay showed that punicalagin was more selective for fungal than mammal cells, indicating its probable best use in clinical applications. These results indicated that the crude extract and punicalagin had a greater antifungal activity against $T$. rubrum, indicating that pomegranate is a good target for study due to its potential future use as a new therapeutic alternative against dermatophytosis.

\section{Competing interests}

The authors declared that they have no competing interests.

\section{Authors' contributions}

SRF carried out the phytochemical and microbiological studies and drafted the manuscript. CVN and TUN participated in microscopy and cytotoxicity assays. DAGC participated in spectroscopic assays. EHE participated with microbiological assays and draft the manuscript. BPDF conceived of the study, and participated in its design and coordination and helped to draft the manuscript. All authors read and approved the final manuscript.

\section{Acknowledgements}

This study was supported by Conselho Nacional de Desenvolvimento Científico e Tecnológico (CNPq), Capacitação e Aperfeiçoamento de Pessoal de Nível Superior, (Capes), Fundação Araucária, and Programa de Pós-graduação em Ciências Farmacêuticas da Universidade Estadual de Maringá. Part of the experiments were carried out at the Complexo de Central de Apoio a Pesquisa (COMCAP) MCT/FINEP/UEM.

\section{Author details}

${ }^{1}$ Post graduation in Microbiology, Universidade Estadual de Londrina, Londrina, PR, Brazil. 'Department of Health Sciences, Universidade Estadual de Maringá, Maringá, PR, Brazil. 'Departament of Pharmacy, Universidade Estadual de Maringá, Maringá, PR, Brazil. ${ }^{4}$ Post graduation in Pharmaceutical Sciences, Universidade Estadual de Maringá, Maringá, PR, Brazil.

Received: 13 December 2013 Accepted: 13 July 2014

Published: 11 March 2015

\section{References}

1. Rinaldi MG: Dermatophytosis: Epidemiological and microbiological update. J Am Acad Dermatol 2000, 43:120-124.

2. Johnson L: Dermatophytes- the skin eaters. Mycologist 2003, 17:147-149.

3. Tsang P, Jimenez-Lucho V: Deep dermatophytosis caused by Trichophyton rubrum in a patient with AIDS. J Am Acad Dermatol 1996, 34:1090-1091.

4. Seçkin D, Haberal M: Deep dermatophytosis caused by Trichophyton rubrum with concomitant disseminated nocardiosis in a renal transplant recipient. J Am Acad Dermatol 2004, 51:173-176.

5. Walsh TJ, Groll A, Hiemenz J, Fleming R, Roilides E, Anaissie E: Infections due to emerging and uncommon medically important fungal pathogens. Clin Microbiol Infect 2004, 10:48-66.

6. Pelegrini A, Takahashi JP, Pereira CQM, Pessoni RB, Souza MC: Incidence of dermatophytosis in a public hospital of São Bernardo do Campo, São Paulo State, Brazil. Ver Iberoam Micol 2009, 26:118-120. 
7. Straten MRV, Hossain MA, Ghannoum MA: Cutaneous infections Dermatophytosis, onychomycosis and Tinea versicolor. Infect Dis Clin North Am 2003, 17:87-112.

8. Meléndrez PA, Capriles VA: Antibacterial properties of tropical plants from Puerto Rico. Phytomedicine 2006, 13:272-276.

9. Al-Zoreky NS: Antimicrobial activity of pomegranate (Punica granatum L.) fruit. Int J Food Microbiol 2009, 134:244-248.

10. Dell'Agli M, Galli GV, Corbett Y, Taramelli D, Lucantoni L, Habluetzel A, Maschi O, Caruso D, Giavarini F, Romeo S, Bhattacharia D, Bosisio E: Antiplasmodial activity of Punica granatum L. fruit rind. J Ethnopharmacol 2009, 125:279-285.

11. Bakkiyaraj D, Nandhini JR, Malathy B, Pandian SK: The antibiofilm potential of pomegranate (Punica granatum L.) extract against human bacterial and fungal pathogens. Biofouling 2013, 29:929-937.

12. Calzada F, Yépez-Mulia L, Aguilar A: In vitro susceptibility of Entamoeba histolytica and Giardia lamblia to plants used in Mexican tradicional medicine for the treatment of gastrointestinal disorders. J Ethnopharmacol 2006, 108:367-370.

13. Osorio E, Flores M, Hernández D, Ventura J, Rodríguez R, Aguilar CN: Biological Efficiency of polyphenolic extracts from pecan nuts Shell (Carya illionensis), pomegranate husk (Punica granatum) and creosote bush leaves (Iarrea tridentate Cov.) against plant pathogenic fungi. Ind Crops Prod 2010, 31:153-157.

14. Vasconcelos LCS, Sampaio MCC, Sampaio FC, Higino JS: Use of Punica granatum as an antifungal agent against candidosis associated with denture stomatitis. Mycoses 2003, 46:192-196.

15. Liu M, Katerere DR, Gray Al, Seidel V: Phytochemical and antifungal studies on Terminalia mollis and Terminalia brachystemma. Fitoterapia 2009, 80:369-373.

16. Clinical and Laboratory Standards Institute: Reference Method for Broth Dilution Antifungals Susceptibility Testing of Conidium-Forming Filamentous Fungi: Approved Standard, M38-A2. 2nd edition. Wayne: CLSl; 2008.

17. Clinical and Laboratory Standards Institute: Methods for Dilution Antimicrobial Susceptibility Test for Bacteria that Grow Aerobically. Approved Standard, M07-A9. 9th edition. Wayne: CLSI; 2012.

18. Prasad NR, Anandi C, Balasubramanian S, Pegalendi KV: Antidermatophyte activity of extracts from Psoralea coryfolia (Fabaceae) correlated with the presence of a flavonoid compound. J Ethnopharmacol 2001, 91:21-24.

19. Koroishi AM, Foss SR, Cortez DAG, Ueda-Nakamura T, Nakamura CV, Dias Filho BP: In vitro antifungal activity of extracts and neolignans from Piper regnelli against dermatophytes. J Ethnopharmacol 2008, 117:270-277.

20. Cunha AP, Silva AP, Roque OR, Cunha E: Plantas e produtos vegetais em cosmética e dermatologia. Lisboa: Editora Fundação Caloustre Gulbenkian; 2004:310.

21. Kulkarni AP, Mahal HS, Kapoor S, Aradhya SM: In vitro studies on the binding, antioxidant, and cytotoxic actions of Punicalagin. J Agric Food Chem 2007, 55:1491-1500.

22. Lu J, Wei Y, Yuan Q: Preparative separation of punicalagin from pomegranate husk by high-speed countercurrent chromatography. J Chromatogr B 2007, 857:175-179.

23. Seeram N, Lee R, Hardy M, Heber D: Rapid large scale purification of ellagitannins from pomegranate husk, a by-product of the commercial juice industry. Sep Purif Technol 2005, 41:49-55.

24. Doig AJ, Williams DH, Oelrichs PB, Baczynsky JL: Isolation and structure elucidation of punicalagin, a toxic hydrolysable tannin, from Terminalia oblonga. J Chem Soc Perkin Trans 1990, 673:2317-2321.

25. Aljabre SHM, Randhawa MA, Akhtar N, Alakloby OM, Algurashi AM, Aldossary A: Antidermatophyte activity of ether extract of Nigella sativa and its active principle, thymoquinone. J Ethnopharmacol 2005, 101:116-119.

26. Svetaz L, Zuljan F, Derita M: Value of the ethnomedical information for the discovery of plants with antifungal properties. A survey among seven Latin American countries. J Ethnopharmacol 2010, 127:137-158.

27. Vidal A, Fallarero A, Peña BR, Medina ME, Gra B, Rivera F, Gutierrez Y, Vuorela PM: Studies on $t$ toxicity of Punica granatum L. (punicaceae) whole fruit extracts. J Ethnopharmacol 2003, 89:295-300.

28. Cerda B, Cerón JJ, Tomás-Barberá T, Espín JC: Repeated oral administration of high doses of the pomegranate ellagitannin punicalagin to rats for 37 days is not toxic. J Agric Food Chem 2003, 51:3493-3501.

doi:10.1186/s12941-014-0032-6

Cite this article as: Foss et al:: Antifungal activity of pomegranate peel extract and isolated compound punicalagin against dermatophytes. Annals of Clinical Microbiology and Antimicrobials 2014 13:32.

\section{Submit your next manuscript to BioMed Central and take full advantage of:}

- Convenient online submission

- Thorough peer review

- No space constraints or color figure charges

- Immediate publication on acceptance

- Inclusion in PubMed, CAS, Scopus and Google Scholar

- Research which is freely available for redistribution 